\title{
Material didático digital para ensino de literatura
}

\author{
Marly Fernandes
}

\begin{abstract}
Resumo
Este artigo apresenta uma proposta de ensino de literatura, tendo por base os gêneros discursivos digitais (microcontos e poemas digitais), objetos culturais híbridos que contemplam diferentes linguagens multimodais e hipermidiáticas, que podem atender às perspectivas dos multiletramentos e dos novos letramentos.
\end{abstract}

Palavras-chave: gêneros discursivos digitais, material didático digital, novos letramentos.

\begin{abstract}
This article presents a teaching proposal for literature classes with a focus on digital speech genres (short-stories and digital poems). These genres are hybrid cultural objects that have several multimodal and hyper modal languages that come within the perspective of multiple literacies and new literacies.
\end{abstract}

Keywords: digital speech genres, digital teaching material, new literacies

\section{INTRODUÇÃO}

Este artigo apresenta algumas discussões de nossa pesquisa, ainda em fase de desenvolvimento, na qual está presente uma proposta de ensino de literatura, tendo por base os gêneros discursivos digitais microcontos e poemas digitais. Eles são objetos culturais híbridos, que contemplam diferentes linguagens multimodais e hipermidiáticas, que podem atender às perspectivas dos multiletramentos e dos novos letramentos, necessárias ao ensino-aprendizagem contemporâneo de literatura no Ensino Médio brasileiro.

As formas composicionais multimodais e hipermidiáticas desses gêneros, bem como as novas linguagens e recursos tecnológicos incorporados em materiais didáticos mais flexíveis e interativos, podem levar esses alunos à apreciação valorativa e responsiva sobre esses enunciados digitais.

Inicialmente procuramos correlacionar, brevemente, algumas das perspectivas para relativas aos multiletramentos e aos novos letramentos, que poderiam servir para sinalizar 
novos caminhos para o ensino-aprendizagem de literatura em contexto de Ensino Médio. Em um segundo momento, apresentamos algumas discussões sobre as novas formas da criação literária digital que podem justificar novas perspectivas de ensino de literatura. Por último, sugerimos alguns aspectos relevantes a se considerar na elaboração de conteúdos de um protótipo de material didático digital para o ensino-aprendizagem de literatura, incorporandoesses novos gêneros discursivos digitais em questão, objetos de nossa pesquisa, quais sejamos microcontos e poemas digitais.

Nossas abordagens tomam por base alguns pressupostos teóricos dos Multiletramentos (COPE e KALANTZIZ, 2006 [2000]), dos Novos Letramentos (COIRO, KNOBEL, LANKSEHEAR e LEU (2008); LANKSHEAR e KNOBEL (2007), dentre outros), alguns dos conceitos das teorias enunciativo-discursivas de Bakhtin e seu Círculo (gêneros do discurso, réplica ativa, estilo linear e estilo pictórico, enunciação concreta, dentre outros), além de pesquisas recentes sobre literatura digital tais como: Castanyer, Adell, Borrás et al (2005); Neitzel (2006, 2008); Santaella (2012); Santos (2005, 2010); Spalding (2008, 2012); Unsworth (2005), dentre outras.

\section{MULTILETRAMENTOS E NOVOS LETRAMENTOS: CAMINHOS PARA O ENSINO DE LITERATURA}

Os novos gêneros discursivos digitais exigem práticas de linguagem para moldarem-se às situações atuais de comunicação e de interação, bem como para a expansão de modos de ler e, consequentemente, capacidades leitoras a eles atreladas, ou seja, que permitam pensar autônoma, reflexiva e criticamente a partir de múltiplas capacidades letradas exigidas pela vida contemporânea.

Esse parece ser um dos novos desafios da escola para dar conta desse cenário, pois "as novas tecnologias diversificam e complexificam continuamente as práticas de linguagem" (BUZATO, 2009, p. 12) e, consequentemente, convocam a necessidade de letramentos diversos para dar conta da multiplicidade de linguagens que os gêneros discursivos digitais oferecem.

Além disso, a pluralidade e a diversidade dos leitores e dos autores dos contextos contemporâneos que circulam fora da escola, notadamente no ambiente digital, solicitam novas perspectivas de leitura que façam sentido para a vida social protagonista e que 
contemplem as múltiplas facetas da vida pessoal do alunado, principalmente de Ensino Médio, reiterando a necessidade de se buscar caminhos de transformações mais amplos no que se refere às concepções de letramentos, para que tenhamos uma educação linguística que faça sentido em contexto escolar contemporâneo para este segmento da Educação Básica.

Nesse sentido, Knobel e Lankshear (2002) registram que há pouca exploração dos gêneros midiáticos que circulam na Internet. $\mathrm{Na}$ ótica dos autores, os materiais ou as tecnologias que podem contribuir para os letramentos (mediados pelos impressos ou pelos virtuais) devem estar sempre relacionados a práticas e contextos situados, que podem levar à produção de sentidos e podem modificar outros já existentes.

Seguindo essa linha de reflexão, Cope e Kalantzis (2006 [2000]) colocam-nos a opção de se trabalhar a partir de propostas que visem aos multiletramentos. Esta perspectiva sugerida pelos autores parece ampliar, mais consistentemente, as questões sobre a educação que se devemos pensar, para que os letramentos sejam efetivamente incorporados de maneira significativa aos alunos, em contexto escolar, para agir no mundo contemporâneo frente aos novos desafios que se fazem sentir em meio à variedade de linguagens, leituras e culturas que circulam na sociedade hoje. Na concepção dos autores, os alunos possuem diversas experiências fora da escola que não podem ser ignoradas.

As culturas digitais emergentes dos jovens impõem desafios às práticas tradicionais que circulam em contexto escolar e podem assumir um papel proativo "ao apresentar tanto perspectivas críticas quanto oportunidades de participação em relação à nova mídia" (BUCKINGHAM, 2010, p. 37). O autor reitera, entretanto, a relevância e o "valor imprescindível da escolarização formal". Considera, também, a pertinência de que a escola busque uma abordagem mais ampla para os letramentos escolares, extrapolando o letramento verbal com a incorporação de letramentos mais abrangentes e, assim, levar as práticas escolares a perspectivas mais críticas e produtivas.

Nessa direção, a escola assume um papel relevante frente a esse cenário, pois conforme registram Beach e O'Brien (2008), mesmo com a crescente diversidade de textos digitais da cultura dos alunos presentes em seu cotidiano, as práticas correntes na escola continuam mais centradas nos textos impressos da tradicional cultura escolar. Isso 
não significa o abandono do texto impresso, entretanto os textos digitais podem otimizar as práticas de leitura com a incorporação de atividades que busquem a construção de sentidos também para as imagens e para elementos sonoros que os textos hipermidiáticos agregam.

Além disso, mesmo com o fácil acesso aos materiais digitais de leitura, os autores consideram a necessidade de orientação aos alunos, principalmente em relação a pesquisas e análises de imagens, vídeos, textos sonoros e verbais, ou até mesmo em relação à busca de ideias que possam orientá-los na compreensão e na posterior elaboração de seus projetos individuais de leitura em relação a esses materiais. Desse modo, esses alunos podem elaborar, criticamente, novas formas de representação de discursos, temas, estilos em suas novas criações, ou seja, responderam ativamente aos objetos (gêneros discursivos diversos) culturais lidos e reconfigurados.

Snyder e Bulfin (2008) também sinalizam que o trabalho com textos digitais hipermidiáticos em sala de aula convoca uma complexa rede de capacidades e habilidades para lidar com o verbal, o visual e o audiovisual. Ainda registram que muitas vezes novos objetos culturais podem circular, indiretamente, nas escolas por iniciativa de alguns professores sem, contudo, fazerem parte dos currículos, no geral, mais tradicionais e não abertos a essa incorporação.

Nessa direção, Leu at al (2009) defendem que as novas tecnologias devem fazer parte dos contextos escolares e extraescolares, indistintamente. Entretanto, sinalizam para que se alargue a visão limítrofe e estreita da escola em relação ao que seja o uso de tecnologias para dar conta do mundo extraescolar desses alunos. Isso significa, na visão dos autores, que as novas tecnologias devem fazer parte do cotidiano escolar, não somente como instrumentos de apropriação tecnológica, mas também como um processo mais amplo, que faça sentido para os alunos em suas atividades dentro e fora da escola.

Essa ampliação ganha respaldo na perspectiva dos novos letramentos que, dentre outros aspectos, podem resultar na hibridização das produções e das apropriações tecnológicas por parte dos alunos e, além disso, podem abrir caminho para transformações em sentido mais amplo e contribuir para que os sujeitos envolvidos no processo de ensino e aprendizagem assumam uma perspectiva crítica e não conformista e, com isso, estejam dispostos a assumir a responsabilidade pela inclusão / exclusão (própria 
/ alunos) nesses letramentos (BUZATO, 2010).

Assim, um dos caminhos para pensarmos em como aproximar a cultura do aluno à cultura escolar podem ser os novos gêneros discursivos digitais (microcontos e poemas digitais) que circulam amplamente na web e que poderiam ser incorporados ao ensino de literatura e, consequentemente às práticas de leitura em sala de aula de Ensino Médio.

\section{NOVAS PERSPECTIVAS PARA O ENSINO DE LITERATURA A PARTIR DAS FORMAS DE CRIAÇÕES LITERÁRIAS DIGITAIS}

Nunca na história da civilização uma nova tecnologia, como a digital, foi pronta e largamente incorporada por tantos, em diferentes lugares e em tão pouco tempo, conforme registram Leu et al (2009). Nessa linha de reflexão, Santaella (2012, p.229) afirma que as novas tecnologias foram igualmente incorporadas à "produção criativa da qual a literatura faz parte".

As linguagens e ferramentas incorporadas às novas formas de criações literárias digitais acentuam tanto "as transformações de maior alcance produzidas pela literatura digital no conceito de texto" (REIS, 2012, p. 43) bem como "a tendência do texto para transpor os limites convencionais, ao intensificar as propostas de interpenetração do verbal com o sonoro e o visual" (REIS, 2012, p. 43). Desse modo, segundo o autor, as linguagens verbais, visuais ou sonoras passam a coexistir "num estado que confunde as modalidades de linguagem" (REIS, 2012, p. 45).

$\mathrm{Na}$ visão deste autor, as novas mídias digitais criam novas potencialidades para as criações literárias e

\footnotetext{
transformam e transtornam desde logo a noção de texto da literatura dominante enquanto realização verbal impressa, logo fixa e inalterável, assim como conferem renovadas possibilidades a características já conceptualizadas em tendências experimentais anteriores ao mesmo tempo que permitem a criação de novas características textuais. (REIS, 2012, p. 46).
}

Na ótica de Koskimaa (2005), antes de pensarmos na concepção de literatura digital, devemos pensar no próprio conceito de literatura. Em sua acepção pragmática, literatura é todo texto publicável em seus mais diversos segmentos de produção e de circulação. Em sua acepção teórica, a literatura para alguns é uma categoria estético- 
cultural, na qual estão incluídos certos gêneros específicos (narrativos, poéticos e dramáticos) e que podem ser representados pela escrita ou de outra maneira.

Muitos consideram acepções mais rigorosas sobre aquilo que pode e deva ser literatura, estabelecendo divisões entre alta literatura e cultura popular, dando preferência ao primeiro para categorizar o termo literatura. Nessa direção, segundo este autor, o conceito de literatura digital pode ser a ampliação do conceito original, tanto em sua acepção pragmática quanto em sua vertente teórica.

Koskimaa (2005) reitera ainda a importância de se considerar o interesse desses jovens tanto por autores e histórias mais contemporâneos quanto por antigos clássicos, que se tornam extensões online da forma impressa de inúmeras narrativas ficcionais. Entretanto, conforme registra o autor, os currículos escolares ainda não incorporaram essas novas maneiras de se construir e de circular narrativas literárias que estão presentes no ambiente digital.

Nesse sentido, torna-se necessário pensar em formas de se incorporar essas novas criações literárias nas práticas de sala de aula. Para tanto, o autor leva em conta algumas diretrizes relevantes para que tal proposta seja considerada, dentre as quais a articulação do livro impresso e das narrativas literárias digitais. Em segunda instância, considera importante incorporar a diversidade de recursos digitais para a compreensão das diferentes dimensões da experiência da leitura literária. Ainda uma terceira proposta seria esboçar caminhos que viabilizassem o trabalho do professor em sala de aula, com a criação de atividades de leitura literária com o uso de recursos e ferramentas digitais.

Unsworth (2005) ressalta que muitos 'nativos digitais' já estão engajados com as novas e com as tradicionais formas de literatura tanto em seu formato digital quanto em sua forma impressa (enquanto outros estão mais fortemente envolvidos com a literatura digital em relação a sua forma impressa mais tradicional). Ocorre, mais extensivamente, a ampliação das possibilidades para estruturar esses novos gêneros digitais em função de novas ferramentas e de novas linguagens digitais que podem complementar as formas originais desses objetos literários que já circulam em sua forma impressa. Além disso, o interesse dos adolescentes nessas novas formas de fazer e de circular literatura tem crescido paralelamente no contato cotidiano desses jovens com as tecnologias digitais.

Assim sendo, novas práticas de sala de aula para o ensino de literatura podem levar 
os alunos a ler, a analisar e a interpretar reflexiva e criticamente esses novos gêneros discursivos digitais, abrindo assim novas possibilidades de compreender e de incorporar outras linguagens (visual e/ou sonora) no processo de leitura desses objetos culturais digitais. Para tanto, consideramos que essas perspectivas podem ser contempladas de maneira mais consistente em novos conteúdos para materiais didáticos digitais.

\section{MATERIAL DIDÁTICO DIGITAL PARA O ENSINO-APRENDIZAGEM DE LITERATURA: UMA PROPOSTA}

Materiais didáticos digitais para ensino de literatura em contexto de Ensino Médio devem levar professores e alunos a serem participantes ativos e colaborativos no processo de ensino e aprendizagem, contemplando aquilo que Lankshear e Knobel (2007) registram como a possibilidade de ampliação discursiva dos alunos.

Assim, a incorporação de conteúdos mais significativos ("meaningful contents") ao contexto escolar pode ampliar a capacidade de percepção e significação dos discursos que são produzidos e circulam em textos diversos, sobretudo aqueles que circulam no ambiente virtual, cuja presença de textos verbais, visuais e sonoros é extremamente significativa. Por serem mais interativos, estes textos podem se tornar conteúdos mais expressivos / representativos para os alunos, pois as práticas de interação virtual, mais colaborativas, podem extrapolar aquelas presentes nos textos impressos.

Desse modo, podem assumir novas posturas / posicionamentos frente aos novos dispositivos digitais ("new ethos stuff") para dar conta desse cenário e, consequentemente, não replicar as mesmas práticas convencionais de letramentos já incorporadas em contexto escolar mesmo com o uso das novas tecnologias digitais.

Para tanto, alguns aspectos devem ser considerados na tentativa de aproximar as novas perspectivas às práticas de sala de aula quando da elaboração desses materiais digitais, dentre os quais:

- Diversidade dos contextos de ensino-aprendizagem;

- Diferenças regionais do contexto brasileiro;

- Possibilidade de atualização constante do acervo de gêneros discursivos digitais, bem como de recursos e ferramentas de diferentes mídias, para que alunos e professores possam elaborar suas produções e projetos; 
- Compartilhamento de projetos coletivos e de produções hipermidiáticas dos alunos;

- Incorporação de acervo de imagens (estática e em movimento), vídeos, objetos interativos, objetos animados, dentre outros;

- Inclusão de links para navegação e para acesso a conteúdos externos para apoio às atividades presentes no material.

Nessa perspectiva, os conteúdos dos materiais para ensinar literatura na ótica dos multiletramentos e dos novos letramentos deveriam objetivar a criação de acervos para que professores e alunos possam elaborar seus projetos literários a partir dos novos gêneros discursivos digitais, bem como disponibilizar ferramentas tecnológicas digitais (Movie Maker, outras ferramentas de edição) que podem contribuir para criação de atividades e projetos hipermidiáticos.

Além disso, devem promover a interação proativa com os elementos hipermidiáticos desses gêneros discursivos digitais, no sentido de buscas as apreciações ativas e responsivas dos seus usuários (professores e alunos) e, com isso, possibilitar a aproximação desses novos gêneros discursivos digitais com aqueles que já produzidos na literatura canônica.

\section{CONSIDERAÇÕES FINAIS}

Devemos levar em conta a necessidade de novas abordagens de ensino e aprendizagem de literatura que se fazem sentir em função das novas tecnologias digitais e das possibilidades de ampliação para os multiletramentos e para os novos letramentos que extrapolem as linguagens verbais (percepção de imagens e de sons que ampliam as construções de sentido no processo de leitura, por exemplo), principalmente em contexto de Ensino Médio, ou seja, na etapa final da Educação Básica.

Nessa perspectiva, consideramos relevante que essas novas abordagens de ensinoaprendizagem de literatura sejam sustentadas por algumas perspectivas mais amplas, como apresentar tanto um corpus de gêneros discursivos digitais (microcontos e poemas digitais) que circulam na web, bem como os ambientes virtuais nos quais eles são produzidos e/ou circulam (portais e blogs literários). 
Desse modo, as atividades propostas a partir desses gêneros discursivos digitais poderiam levar os alunos, por exemplo, a contrapor as formas composicionais, os estilos e os temas dos novos poemas e contos digitais em relação aos poemas e contos tradicionais, mais comumente apresentados em sua forma impressa ou mesmo disponibilizados na web ou nos livros didáticos que já circulam em sala de aula.

Além disso, as atividades poderiam confrontar esses mesmos elementos presentes nesses gêneros digitais da esfera literária (estrutura, estilo autoral e tema) a outros produzidos em outras esferas, como os curtas-metragens, levando assim professores e alunos à relação e à percepção de temas comuns e das diferentes formas de significar quando há mudança nas esferas de circulação desses gêneros.

Assim sendo, deveríamos pensar em projetos curriculares mais amplos, nos quais os alunos pudessem ter maior participação e protagonismo, pudessem agir de maneira colaborativa, a partir de novos objetos culturais e ferramentas digitais, aproximando, desse modo, suas vivências escolares e extraescolares.

Esse é um dos desafios colocados pelos multiletramentos, pelos novos letramentos e pelas novas tecnologias digitais, que requer uma compreensão mais ampla de como poderíamos incorporar, nesses materiais didáticos digitais, os gêneros discursivos digitais como objetos de ensino de leitura.

\section{REFERENCIAS}

BEACH, R.; O'BRIEN, D. Teaching popular-culture texts in the classroom. In: COIRO et al. (Eds.). The handbook of research in new Literacies. Mahwah, NJ: Erlbaum, 2008, p. 775-804.

BUCKINGHAM, David. Cultura digital, educação mediática e o lugar da escolarização. Educação \& Realidade, v. 35, n. 3, p. 37 - 58, UFRS, 2010.

BUZATO, M. E. K. (a). Letramento e inclusão: do estado-nação à era das TIC. DELTA Documentação de Estudos em Linguística Teórica e Aplicada, v. 25, p. 1-38, 2009.

BUZATO, M. E. K. Cultura digital e apropriação ascendente: apontamentos para uma educação 2.0. Educação em Revista, v. 26, n.3, p. 283-303, 2010.

COPE, B.; KALANTZIS, M. Designs for social futures. In: COPE, B; KALANTZIS, M. (Eds.). Multiliteracies: Literacy learning and the design of social futures. New York: 
Routhledge, 2006[2000]. p. 203-234.

KNOBEL, M.; LANKSHEAR, C. Critical cyberliteracies: what young people can teach us about reading and writing the world? Keynote paper presented at the National Council of English Teachers' Assembly for Research Mid-Winter Conference. New York, February 22-24, 2002. Disponível em: http://www.everydayliteracies.net/cyberliteracies.html. Acesso em: 14 jun. 2013.

KOSKIMAA, R. Qué es la literatura digital? Uma panorâmica general de la literatura digital: de los archivos de texto a los e-books. In: BORRÀS et al (Eds). Textualidades electrónicas - Nuevos escenarios para la literatura. Barcelona: Editorial UOC (Universitat Oberta de Catalunya), 2005, $1^{\text {a }}$ edição, p. 81-94.

LANKSHEAR, C. The "stuff" of new literacies. Crafted with care for the Mary Lou Fulton Symposium by C\&\#9786;1;\&\#8745; £@\&\#8745;k\$\&\#1106;3@®, 2007. Disponível em: http://www.everydayliteracies.net/stuff.pdf. Acesso em: 14 jun. 2013.

LEU, D. J.; O’BYRNE, W. I.; ZAWILINSKI, L.; McVERRY, J. G.; EVERETTCACOPARDO, H. Expanding the New Literacies Conversation. Educational Researcher, $\mathrm{n}^{\mathrm{o}} \quad 38, \quad$ p. 264, 2009. Disponível em: http://edr.sagepub.com/cgi/content/abstract/38/4/264. Acesso em: 14 jun. 2013.

REIS, P. Media digitais: novos terrenos para a expansão da textualidade. In: Cibertextualidades. v.3. p. 43-52. Disponível em: http//:cibertextualidades.ufp.pt. Acesso em: 14 jun. 2013.

SNYDER, I.; BULFIN, S. Using New Media in the Secondary English Classroom. . In: COIRO et al. (Eds.). The handbook of research in new Literacies. Mahwah, NJ: Erlbaum, 2008, p. 805-837.

SANTAELlA, L. Para compreender a ciberliteratura. In: Texto Digital, v.8,n.2,p.229240,jul/dez.2012.

UNSWORTH, L. E-Literature and On-line Literary Resources: Engaging 'Net-Age' Children with New Forms of Literary Texts. Synergy, v. 5, nº 2, 2005.

\section{A AUTORA}

Marly Aparecida Fernandes - Doutoranda, IEL Unicamp

E-mail: myanandes@gmail.com 